\title{
Vitamin D supplementation: Pearls for practicing clinicians
}

\section{ABSTRACT}

Vitamin D supplementation is common in the United States, with about one-fifth of the adult population taking a daily supplement in one form or another. Although the detrimental effects of insufficient sun exposure in childhood was established centuries ago, the beneficial effects of vitamin $D$ sufficiency have only recently been established, given the myriad investigations associating vitamin $\mathrm{D}$ deficiency with numerous chronic diseases. But it is far less clear precisely how to replete low 25-hydroxyvitamin D (25[OH]D) levels, how long treatment should be continued, if there are potential hazards in doing so, and how to assess and counsel patients regarding the use of vitamin D. This article provides a brief historical review, examines how to assess and counsel patients on the use of vitamin $D$, presents scenarios that clinicians are likely to encounter, and reviews the literature on recommendations for vitamin $\mathrm{D}$ supplementation.

\section{KEY POINTS}

Typical vitamin $D$ replacement requires at least 2,000 IU/ day, with some authors recommending 5,000 IU/day.

The richest food sources of vitamin $D$, consumed in manageable portions, provide only a small percentage of the recommended daily intake of $800 \mathrm{IU}$.

Several mechanisms contribute to the ability of vitamin $D_{3}$ to attain and maintain goal serum concentrations of $25(\mathrm{OH}) \mathrm{D}$ more efficiently than vitamin $\mathrm{D}_{2}$, including that vitamin $D_{2}$ has a lower affinity for $D$ binding protein and D 25-hydroxylase converts $\mathrm{D}$ to $25(\mathrm{OH}) \mathrm{D}_{3}$ substantially faster.
V ITAMIN D SUPPLEMENTATON is ubiquitous in the United States, and 20\% of all adults take a dietary supplement containing vitamin D. Supplement use is highest in the very young and in people age 60 and older. ${ }^{1}$ Observations of the detrimental effects of inadequate sun exposure date back centuries. In 1650, scientists noted that children who lived in polluted and crowded cities in Northern Europe developed debilitating skeletal abnormalities, including bowed legs. ${ }^{2}$ In the 1890s, epidemiologic studies in Great Britain noted the higher incidence of significant skeletal abnormalities in children in industrialized cities compared with those who lived in rural areas of the British highlands. ${ }^{3}$ In the United States, it took until the 1920s to achieve wide acceptance that routinely exposing children to sunshine could prevent debilitating skeletal abnormalities. ${ }^{4}$

During the 18th and 19th centuries, codliver oil was commonly used to prevent and treat skeletal abnormalities in children. ${ }^{5}$ The antirachitic factor of cod-liver oil was later isolated and became known as vitamin D. Investigations early in the 20th century led to the vitamin $\mathrm{D}$ fortification of milk and infant formulas that became common practice by the 1930s. As a result, rickets, once the most common disease in children, was eradicated in the United States 100 years ago.

\section{VITAMIN D DEFICIENCY AND CURRENT RECOMMENDATIONS}

Eradication of rickets was a giant step forward in skeletal health of youngsters. However, fortifying foods and beverages with enough vitamin D to prevent rickets but avoid hypercalcemia did not eliminate vitamin D deficiency. 


\section{TABLE 1}

\section{Minimum requirements for vitamin D as defined by the Endocrine Society guidelines}

\begin{tabular}{|c|c|c|}
\hline $\begin{array}{l}\text { Patient } \\
\text { characteristics }\end{array}$ & $\begin{array}{l}\text { Minimum } \\
\text { requirement }\end{array}$ & Comments $^{\mathrm{a}}$ \\
\hline Age 19-50 & 600 IU/day & $\begin{array}{l}\text { Increasing and maintaining the } 25(\mathrm{OH}) \mathrm{D} \text { level consis- } \\
\text { tently above } 30 \mathrm{ng} / \mathrm{mL} \text { may require at least } 1,500-2,000 \\
\text { IU/day }\end{array}$ \\
\hline Age $51-70$ & 600 IU/day & To maximize bone health and muscle function \\
\hline Age $\geq 65$ & 800 IU/day & For the prevention of falls and fractures \\
\hline $\begin{array}{l}\text { Pregnant and lactating } \\
\text { female patients }\end{array}$ & 600 IU/day & $\begin{array}{l}\text { At least } 1,500-2,000 \mathrm{IU} / \text { day may be needed to maintain } \\
\text { a blood level of } 25(\mathrm{OH}) \mathrm{D} \text { above } 30 \mathrm{ng} / \mathrm{dL}\end{array}$ \\
\hline Adults with obesity & & $\begin{array}{l}\text { Give at least } 2 \text { to } 3 \text { times more vitamin } D \text { to meet bodily } \\
\text { requirements }\end{array}$ \\
\hline
\end{tabular}

a With the recommendation not to exceed 4,000 IU daily maintenance dose.

IU = international units; $25(\mathrm{OH}) \mathrm{D}=25$-hydroxyvitamin $\mathrm{D}$

Based on information in reference 10.

Vitamin D deficiency is common in the United States and around the globe. The most common cause of deficiency is insufficient intake (oral or dermal). In a study using National Health and Nutrition Examination Survey (NHANES) data from 2011 to 2014, almost $20 \%$ of the US population had serum 25-hydroxyvitamin D $(25[\mathrm{OH}] \mathrm{D})$ values categorized as "at risk for inadequacy" (defined as 30 to 49 $\mathrm{nmol} / \mathrm{L}$ or 12 to $19 \mathrm{ng} / \mathrm{mL}$ ), and $5 \%$ were categorized as "at risk for deficiency" $(<30 \mathrm{nmol} / \mathrm{L}$ or $12 \mathrm{ng} / \mathrm{mL}) .{ }^{6}$ These reference ranges may be lower than what most clinicians consider to be deficient. For example, numerous studies have found a recommended threshold of $50 \mathrm{nmol} / \mathrm{L}$ $(20 \mathrm{ng} / \mathrm{mL}$ ) for bone health to be insufficient for fall or fracture risk reduction. ${ }^{?}$

\section{Immunologic effects}

Vitamin D supplementation to prevent and treat immune-related diseases including $\mathrm{CO}$ VID-19 was reviewed by Charoenngam et al. ${ }^{8}$ In an extensive examination of the immunologic effects of vitamin D supplements, the authors described the immunomodulatory hormonal effects of vitamin $\mathrm{D}$, noted significant biologic effects on the innate and adaptive immune systems, cited the immunomodulatory and antiviral effects of the active form of vitamin $\mathrm{D}$ (1,25 dihydroxyvitamin D), and suggested that vitamin D supplementation might reduce the risk and severity of COVID-19 infection. They concluded that although the optimal level of vitamin $\mathrm{D}$ remains unclear, maintaining a serum $25(\mathrm{OH}) \mathrm{D}$ level of 100 to $150 \mathrm{nmol} / \mathrm{L}$ (40 to $60 \mathrm{ng} / \mathrm{mL}$ ) is recommended. ${ }^{8}$

As reported at an American Academy of Dermatology conference in $2005,{ }^{9}$ repeated exposure to ultraviolet (UV) light activates both the innate and adaptive arms of the immune system, and UV light from solar radiation has dose-dependent effects on cells, with cellular and DNA damage that can cause immunosuppression. ${ }^{9}$

\section{Guidelines for replacement}

In 2011, the Endocrine Society issued clinical practice guidelines that defined vitamin D deficiency as less than $30 \mathrm{ng} / \mathrm{mL}$ and recommended minimum replacement dosages (Table 1). ${ }^{10}$

The guidelines identify minimum requirements to maximize bone health and muscle function. However, achieving blood levels above $30 \mathrm{ng} / \mathrm{mL}$ (which is considered below normal or low-normal in most laboratory reference ranges) may require more than 2,000
Vitamin D deficiency is common worldwide 


\section{TABLE 2}

\section{Vitamin D content of selected foods}

\begin{tabular}{|c|c|c|c|}
\hline Food & $\begin{array}{l}\text { Micrograms } \\
\text { per serving }\end{array}$ & $\begin{array}{l}\text { International } \\
\text { units } \\
\text { per serving }\end{array}$ & $\begin{array}{l}\text { Percent } \\
\text { of daily value }\end{array}$ \\
\hline Cod-liver oil, 1 tablespoon & 34.0 & 1,360 & 170 \\
\hline Trout (rainbow), farmed, cooked, 3 ounces & 16.2 & 645 & 81 \\
\hline Salmon (sockeye), cooked, 3 ounces & 14.2 & 570 & 71 \\
\hline Mushrooms, white, raw, sliced, exposed to ultraviolet light, $1 / 2$ cup & 9.2 & 366 & 46 \\
\hline Milk, $2 \%$ milkfat, vitamin $D$ fortified, 1 cup & 2.9 & 120 & 15 \\
\hline Soy, almond, and oat milks, vitamin D fortified & $2.5-3.6$ & $100-144$ & $13-18$ \\
\hline $\begin{array}{l}\text { Ready-to-eat cereal, fortified with } 10 \% \text { of the daily value } \\
\text { for vitamin } D, 1 \text { serving }\end{array}$ & 2.0 & 80 & 10 \\
\hline Sardines (Atlantic), canned in oil, drained, 2 sardines & 1.2 & 46 & 6 \\
\hline Egg, 1 large, scrambled & 1.1 & 44 & 6 \\
\hline Liver, beef, braised, 3 ounces & 1.0 & 42 & 5 \\
\hline Tuna (light), canned in water, drained, 3 ounces & 1.0 & 40 & 5 \\
\hline Cheese, cheddar, 1 ounce & 0.3 & 12 & 2 \\
\hline
\end{tabular}

IU daily. Patients with obesity may require several times that dose to attain and maintain a normal level. The Endocrine Society guidelines, in addressing the issue of assay variability, note that in the clinical setting, achieving a level of $40 \mathrm{ng} / \mathrm{mL}$ will not result in toxicity but will ensure that an individual's true value is greater than $30 \mathrm{ng} / \mathrm{mL} .{ }^{10}$

Investigators have considered whether a predictive equation could help clinicians select the correct replacement dose of vitamin $\mathrm{D}$ for their patients. Singh et $\mathrm{al}^{11}$ addressed this question with a retrospective observational study. After reviewing the response to vitamin $\mathrm{D}$ supplementation in more than 1,300 ambulatory and nursing home patients and employing multiple regression analyses, they published a series of equations that predict the dose of vitamin $\mathrm{D}$ needed to achieve a given change in the serum concentration of
$25(\mathrm{OH}) \mathrm{D}$ in these patient populations. Their equation for calculating the dose in international units (IU) that incorporates body mass index $(\mathrm{BMI})$ was as follows ${ }^{11}$ :

Dose in IU = $[(8.52-$ desired change in $25(\mathrm{OH}) \mathrm{D})+(0.07 \times$ age $)$ $-(0.20 \times \mathrm{BMI})+(1.74 \times$ serum albumin $)$

$-(0.62 \times$ starting $25[\mathrm{OH}] \mathrm{D}$ concentration $)] /(-0.002)$

Singh et al speculated that lack of sun exposure explained the need for higher doses of vitamin $\mathrm{D}$ in nursing home patients, since their analyses concluded that increased age alone was not a negative factor in response to vitamin $\mathrm{D}$ treatment. ${ }^{11}$ Their analyses did not address the duration of treatment, but Singh et al acknowledged that many patients require long-term maintenance therapy. They further observed that 5,000 IU per day is usually needed to correct deficiency, and a typical maintenance dose should be at least 2,000 IU daily. ${ }^{11}$ 


\section{HOW TO REPLACE VITAMIN D}

Vitamin D dietary supplements are widely available, and in 2020, the industry's estimated market value exceeded $\$ 1.1$ billion, projected to reach close to $\$ 1.6$ billion by $2025 .{ }^{12}$ The annual growth rate is more than $7 \%$ due to people paying more attention to their nutrition and their health in general.

The popularity of vitamin D supplements has been fueled at least in part by campaigns educating the public about the risks of skin cancer due to excess sun exposure, the association of vitamin $\mathrm{D}$ deficiency with many chronic diseases, and the association of vitamin D levels with optimal immune function.

Vitamin D supplements are available by prescription, over-the-counter, and online. In 2021 , the cost per 100 tablets of 2,000 IU vitamin $D_{3}$ was around $\$ 0.05$ per tablet, while 100 capsules of $50,000 \mathrm{IU}$ vitamin $\mathrm{D}_{2}$ or $\mathrm{D}_{3}$ started at $\$ 0.25$ per capsule.

\section{Is it possible to get sufficient vitamin D exclusively from diet?}

Despite fortification of commonly consumed products such as milk, food sources of vitamin $\mathrm{D}$ are few, and even the richest sources consumed in manageable portions provide only a small percentage of the recommended daily intake (Table 2). ${ }^{1}$

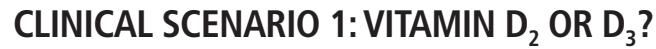

An otherwise healthy 30-year-old woman with a BMI of $37 \mathrm{~kg} / \mathrm{m}^{2}$ was referred for vitamin D deficiency "unresponsive to D repletion." Her initial 25(OH)D level was $14 \mathrm{ng} / \mathrm{mL}$. After taking vitamin $\mathrm{D}_{2}$ at a dose of 50,000 IU once weekly with her morning coffee for 4 weeks, her $25(\mathrm{OH}) \mathrm{D}$ level remained at $21 \mathrm{ng} / \mathrm{mL}$, still below the normal range.

The clinical challenges with this patient are to consider whether vitamin $D_{2}$ (ergocalciferol) or $\mathrm{D}_{3}$ (cholecalciferol) makes a difference, and whether taking it on an empty stomach is optimal for absorption.

Several recent articles have addressed the question of whether $\mathrm{D}_{2}$ and $\mathrm{D}_{3}$ supplements are equivalent in raising serum $25(\mathrm{OH}) \mathrm{D} \cdot{ }^{13-15}$ Houghton and Vieth ${ }^{13}$ questioned assumptions about their equivalency and proposed several mechanisms that may contribute to the ability of vitamin $\mathrm{D}_{3}$ to maintain higher serum concentrations over time, including the following:

- Supplementation with vitamin $\mathrm{D}_{2}$ produces serum $25(\mathrm{OH}) \mathrm{D}_{2}$, but its lower affinity for $\mathrm{D}$ binding protein results in a shorter half-life than that of $25(\mathrm{OH}) \mathrm{D}_{3}$

- Mitochondrial vitamin D 25-hydroxylase converts vitamin $\mathrm{D}_{3}$ to $25(\mathrm{OH}) \mathrm{D}_{3}$ five times faster than it converts vitamin $\mathrm{D}_{2}$ to $25(\mathrm{OH}) \mathrm{D}_{2}$.

In a systematic review and meta-analysis, Tripkovic et $\mathrm{al}^{14}$ concluded that supplementation with vitamin $\mathrm{D}_{3}$ had a significant and positive effect in the raising of serum $25(\mathrm{OH})$ D concentrations compared with the effect of $\mathrm{D}_{2}(P=.001)$. In a study that explored the relative potency of vitamin $\mathrm{D}_{2}$ and vitamin $\mathrm{D}_{3}$, Armas et $\mathrm{al}^{15}$ found the 2 forms to be equivalent in absorption. Further, they both produced similar increases in serum $25(\mathrm{OH})$ D in the first 72 hours, but the $25(\mathrm{OH}) \mathrm{D}$ level continued to rise in the $\mathrm{D}_{3}$-treated patients, peaking at day 14 . Their calculated area under the curve at 28 days indicated that $\mathrm{D}_{3}$ was 9.5 times more potent than $\mathrm{D}_{2}$.

\section{Any difference in how it is taken?}

Does it matter if the supplement is taken on an empty stomach vs with a meal? In a small study, Mulligan and Licata ${ }^{16}$ found that taking either vitamin $\mathrm{D}_{2}$ or $\mathrm{D}_{3}$ with the largest meal of the day increased the average serum $25(\mathrm{OH}) \mathrm{D}$ level by $50.2 \%$ ( $\pm 13.4 \%)$.

Similarly, a systematic review by Silva and Furlanetto ${ }^{17}$ included randomized controlled trials examining the response to a single dose of vitamin $D$ taken with a fat-free meal vs meals that contained $15 \mathrm{~g}$ or more of fat. Mean serum 25(OH)D concentrations were higher in those who took the supplement with a meal that included at least $15 \mathrm{~g}$ of fat. ${ }^{17}$

\section{Recommended treatment for this patient}

This 30-year-old female patient, deemed unresponsive to vitamin $\mathrm{D}$ repletion, was treated with vitamin $\mathrm{D}_{3} 50,000$ IU weekly for 8 weeks taken with dinner. Her 25(OH)D level rose to $42.8 \mathrm{ng} / \mathrm{mL}$.

\section{CLINICAL SCENARIO 2: PHOTOTHERAPY TO COUNTER MALABSORPTION?}

A 38-year-old man with a history of fistuliz-

\section{Thresholds for vitamin D deficiency vary among organizations}


ing Crohn disease had undergone multiple small-bowel resections and had become dependent on parenteral nutrition. His $25(\mathrm{OH})$ D level was $12 \mathrm{ng} / \mathrm{mL}$ despite taking vitamin $\mathrm{D}_{2}$ 50,000 IU daily. In an effort to overcome his malabsorption issue, he would bite into the gel cap to release the contents before swallowing the supplement.

Dual $\mathrm{x}$-ray absorptiometry was notable for an extraordinarily low hip Z-score of -3.4, his long bones were painful to palpation, and his parathyroid hormone level was significantly elevated at $248 \mathrm{pg} / \mathrm{mL}$ (reference range 15-65 $\mathrm{pg} / \mathrm{mL}$ ). Osteomalacia is not uncommon in this patient population, but treating the vitamin $\mathrm{D}$ deficiency can be very challenging.

In addition to Crohn disease, other conditions can interfere with vitamin $\mathrm{D}$ absorption, including a history of malabsorptive-type bariatric surgery, celiac disease, cystic fibrosis, steatorrhea, short bowel disease, inflammatory bowel disease, and severe cholestasis. ${ }^{17} \mathrm{~A}$ vitamin D challenge test is one way to confirm the absorptive capability for vitamin D supplementation in these patients.

When vitamin $\mathrm{D}$ is taken orally, it is incorporated into the chylomicron fraction, Suntanning and tanning booths are not therapies for vitamin D deficiency

the lymphatics. The blood level of $25(\mathrm{OH}) \mathrm{D}$ will peak about 12 hours after a single dose of 50,000 IU. Knowing this about oral absorption of vitamin $\mathrm{D}$ allows for provocative testing in patients with suspected malabsorption of the vitamin.

To test for malabsorption, a blood sample dermatology for phototherapy. UV-B light was administered 3 days per week under the close supervision of an experienced dermatologist, and his $25(\mathrm{OH}) \mathrm{D}$ level rose to $48 \mathrm{ng} / \mathrm{mL}$ within a few weeks.

\section{Sunbathing and tanning booths: A word of caution}

Sunbathing and tanning booths are not therapies for vitamin D deficiency. Sunshine is composed of approximately 95\% UV-A and $5 \% \mathrm{UV}-\mathrm{B}$, but only UV-B is required for vitamin D synthesis. UV-A is the predominant or sole light source used in tanning beds, and the dose of UV-A in tanning beds can be up to 12 times that provided by the sun. ${ }^{19}$

Skin cancers comprise one-half of all cancers, and UV-A and UV-B are both implicated. UV-A is thought to damage skin and increase the risk of melanoma by causing oxidative stress-induced DNA damage. UV-B damage is more direct, with photoproducts that are implicated in skin carcinogenesis. Skin type and age are factors in the response to UV exposure, but in general, exposing $5 \%$ of the body surface twice weekly for 20 minutes during the summer months may be equivalent to 430 IU of vitamin D per day, with a plateau being reached after 20 minutes. ${ }^{9}$ is drawn immediately before administering a $50,000-\mathrm{IU}$ oral dose of vitamin D. The blood draw is repeated in 12 to 24 hours. If no increase in $25(\mathrm{OH}) \mathrm{D}$ is noted, the patient has "complete" malabsorption of vitamin D. ${ }^{18}$ Incidentally, if this is the finding, then the patient may need testing for deficiencies of other fat-soluble vitamins such as vitamin A.

In addition to supplementation, vitamin D synthesis can take place when the skin is exposed to UV-B light. The therapeutic benefits of phototherapy are recognized for a wide variety of skin conditions, and with careful skin-typing and carefully metered exposure to UV-B light, phototherapy can also achieve normal 25(OH)D levels. ${ }^{9,19}$

This 38-year-old patient was referred to

\section{CLINICAL SCENARIO 3: VITAMIN D DEFICIENCY WITH HYPERCALCEMIA}

A 78-year-old otherwise healthy woman with primary hyperparathyroidism also has vitamin $\mathrm{D}$ deficiency, with a $25(\mathrm{OH}) \mathrm{D}$ level of $15 \mathrm{ng} / \mathrm{mL}$ in the presence of an elevated serum calcium level of $11.4 \mathrm{mg} / \mathrm{dL}$ (reference range $8.5-10.2 \mathrm{mg} / \mathrm{dL}$ ), high parathyroid hormone of $128 \mathrm{pg} / \mathrm{mL}$ (reference range 15-65 $\mathrm{pg} / \mathrm{mL}$ ), low phosphorus of $1.7 \mathrm{mg} / \mathrm{dL}$ (reference range 3.0-4.5 mg/dL), and high 24-hour urine calcium of $472 \mathrm{mg}$ (reference range 100-300/day).

In a meta-analysis of 10 studies that included 340 patients with primary hyperparathyroidism, Shah et $\mathrm{al}^{20}$ assessed the effect of $25(\mathrm{OH}) \mathrm{D}$ replacement in patients with coexistent vitamin D deficiency. The studies included the use of vitamin $\mathrm{D}_{2}$ and $\mathrm{D}_{3}$ supplements, and the time span of administration ranged from 1 to 12 months. Interestingly, this study noted a nonsignificant but modest 
decline in serum calcium after vitamin $\mathrm{D}$ replacement. Only 2.2\% developed more severe hypercalcemia ( $>12 \mathrm{mg} / \mathrm{dL}$ ) that responded to stopping the supplement or to reducing the dose. The authors concluded that vitamin D replacement in patients with primary hyperparathyroidism does not worsen hypercalcemia.

This patient was placed on $5,000 \mathrm{IU}$ of vitamin $\mathrm{D}_{3}$ daily, taken with her largest meal, and was maintained on that dose following parathyroid surgery. At her 3-month postoperative visit, the $25(\mathrm{OH}) \mathrm{D}$ level was normal at $52 \mathrm{ng} / \mathrm{mL}$, and her parathyroid hormone and serum calcium levels were also normal.

\section{A word of caution: Vitamin D toxicity}

Vitamin D toxicity can result from overcorrection of vitamin $\mathrm{D}$ deficiency. Case reports have implicated manufacturing errors, overdosing by patients or prescribers, or a combination of these factors. ${ }^{21}$ Perhaps no report is more poignant than the report by Zhou et $\mathrm{al}^{22}$ of an 80 -year-old man who presented with signs and symptoms consistent with vitamin D toxicity including confusion, dysarthria, and ataxic gait, and was found to have a serum calcium of $14.4 \mathrm{mg} / \mathrm{dL}$ in the presence of a parathyroid hormone level of $11 \mathrm{pg} / \mathrm{mL}$ and $25(\mathrm{OH}) \mathrm{D}$ of $365 \mathrm{ng} / \mathrm{mL}$. He had been prescribed a weekly 50,000-IU vitamin D tablet, but at some point, he began to take it daily with his other medications. All of his symptoms resolved after a brief hospital stay, during which the vitamin D supplement was stopped and the hypercalcemia was addressed.

\section{CLOSING THOUGHTS}

Vitamin D deficiency is relatively common. The detrimental effects of vitamin D deficiency have been well documented, dating to the 1600 s, but only during the early 1900 s did we discover and implement palatable fortification of milk and other foods that led to the eradication of rickets in children. However, fortification of milk alone failed to eliminate vitamin $\mathrm{D}$ deficiency.

Fortunately, vitamin D supplements are easily prescribed, inexpensive, and available over the counter. It is important for clinicians to be attentive to the likelihood of vitamin $\mathrm{D}$ deficiency, especially in patients with certain diseases and conditions; to advise patients on the best ways to attain and maintain an adequate $25(\mathrm{OH}) \mathrm{D}$ level; to counsel patients taking supplements on avoiding oversupplementation; to advise against inappropriate reliance on sun exposure and tanning beds for vitamin D supplementation; and to recognize symptomatic vitamin $\mathrm{D}$ toxicity.

\section{DISCLOSURES}

The author reports no relevant financial relationships which, in the context of her contributions, could be perceived as a potential conflict of interest.

\section{REFERENCES}

1. National Institutes of Health, Office of Dietary Supplements. Vitamin D. https://ods.od.nih.gov/factsheets/VitaminD-HealthProfessional/. Accessed February 13, 2022.

2. Fraser D, Scriver CR. Hereditary disorders associated with vitamin $D$ resistance or defective phosphate metabolism. In: DeGroot LJ. Endocrinology. New York, NY: Grune \& Stratton; 1979:797-807.

3. Owens I. Reports of the Collective Investigation Committee of the British Medical Association. Geographical distribution of rickets, acute and subactute rheumatism, chorea and urinary calculus in the British Islands. Br Med J 1889; 1:113-116.

4. Holick M. Vitamin D. In: Shils ME, Olson JA, Shine M, et al. Modern Nutrition in Health and Disease. 9th ed. Baltimore, MD: Williams \& Wilkins; 1999:329-345.

5. Mayer J. Armand Trousseau and the arrow of time. Nutr Rev 1957; 15(11):321-323. doi:10.1111/j.1753-4887.1957.tb00424.x

6. Herrick KA, Storandt RJ, Afful J, et al. Vitamin D status in the United States, 2011-2014. Am J Clin Nutr 2019; 110(1):150-157. doi:10.1093/ajcn/nqz037

7. Liu X, Baylin A, Levy PD. Vitamin D deficiency and insufficiency among US adults: prevalence, predictors and clinical implications. $\mathrm{Br}$ J Nutr 2018; 119(8):928-936. doi:10.1017/S0007114518000491

8. Charoenngam N, Holick MF. Immunologic effects of vitamin D on human health and disease. Nutrients 2020; 12(7):2097. doi:10.3390/nu12072097

9. Lim HW, Gilchrest BA, Cooper KD, et al. Sunlight, tanning booths, and vitamin D. J Am Acad Dermatol 2005; 52(5):868-876. doi:10.1016/j.jaad.2005.03.015

10. Holick MF, Binkley NC, Bischoff-Ferrari HA, et al. Evaluation, treatment, and prevention of vitamin D deficiency: an Endocrine Society clinical practice guideline. J Clin Endocrinol Metab 2011; 96(7): 1911-1930. doi:10.1210/jc.2011-0385

11. Singh G, Bonham AJ. A predictive equation to guide vitamin D replacement dose in patients. J Am Board Fam Med 2014; 27(4): 495-509. doi:10.3122/jabfm.2014.04.130306

12. MarketsandMarkets. Vitamin D market worth $\$ 1.6$ billion by 2025 . https://www.marketsandmarkets.com/PressReleases/vitamin-d.asp. Accessed February 13, 2022.

13. Houghton LA, Vieth $\mathbf{R}$. The case against ergocalciferol (vitamin $D_{2}$ ) as a vitamin supplement. Am J Clin Nutr 2006; 84(4):694-697. doi:10.1093/ajcn/84.4.694

14. Tripkovic L, Lambert $H$, Hart $K$, et al. Comparison of vitamin $D_{2}$ and vitamin $D_{2}$ supplementation in raising serum 25 -hydroxyvitamin $D$ status: a systematic review and meta-analysis. Am J Clin Nutr 2012; 95(6):1357-1364. doi:10.3945/ajcn.111.031070

15. Armas LA, Hollis BW, Heaney RP. Vitamin $D_{2}$ is much less effective than vitamin $D_{3}$ in humans. J Clin Endocrinol Metab 2004; 89(11):5387-5391. doi:10.1210/jc.2004-0360

16. Mulligan GB, Licata A. Taking vitamin D with the largest meal 
improves absorption and results in higher serum levels of 25-hydroxyvitamin D. J Bone Miner Res 2010; 25(4):928-930. doi:10.1002/jbmr.67

17. Silva MC, Furlanetto TW. Intestinal absorption of vitamin D: a systematic review. Nutr Rev 2018; 76(1):60-76. doi:10.1093/nutrit/nux034

18. Lo CW, Paris PW, Clemens TL, Nolan J, Holick MF. Vitamin D absorption in healthy subjects and in patients with intestinal malabsorption syndromes. Am J Clin Nutr 1985; 42(4):644-649. doi:10.1093/ajcn/42.4.644

19. Sample A, He YY. Mechanisms and prevention of UV-induced melanoma. Photodermatol Photoimmunol Photomed 2018; 34(1):13-24. doi:10.1111/phpp.12329

20. Shah VN, Shah CS, Bhadada SK, Rao DS. Effect of $25(\mathrm{OH})$ D replace- ments in patients with primary hyperparathyroidism (PHPT) and coexistent vitamin D deficiency on serum $25(\mathrm{OH}) \mathrm{D}$, calcium and PTH levels: a meta-analysis and review of literature. Clin Endocrinol (Oxf) 2014; 80(6):797-803. doi:10.1111/cen.12398

21. Galior K, Grebe S, Singh R. Development of vitamin D toxicity from overcorrection of vitamin $D$ deficiency: a review of case reports. Nutrients 2018; 10(8):953. doi:10.3390/nu10080953

22. Zhou K, Assalita S, Williams SE. Confusion and hypercalcemia in an 80-year-old man. Cleve Clin J Med 2017; 84(4):281-286. doi:10.3949/ccjm.84a.16017

Address: Susan E. Williams, MS, RD, MD, CDE, FACE, FAND, Endocrinology and Metabolism Institute, F20, Cleveland Clinic, 9500 Euclid Avenue, Cleveland, OH 44195; willias9@ccf.org

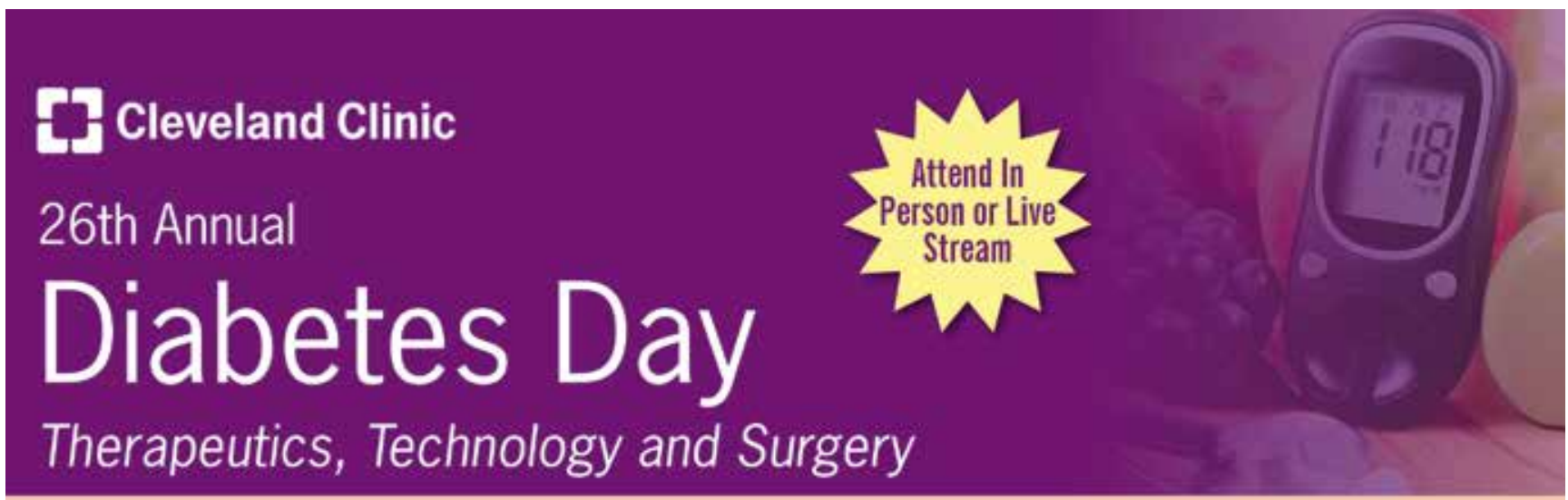

Thursday, May 5, 2022 InterContinental Hotel and Conference Center | Cleveland, $\mathrm{OH}$ and Live Stream

This course will provide up-to-date reviews of management strategies and research on the complications of diabetes. Key topic areas that will be addressed include a review of therapeutic options to manage both type 1 and 2 diabetes and their complications, including a pump update, smart pens review, continuous glucose monitoring interpretation and use in the hospital, importance of obesity management vs diabetes control, hypertension goals and management, new roles for GLPI agonists and SGLT-2 inhibitors, diabetes and pregnancy in type 1 and type 2 diabetes, and treatment of hypoglycemia. New this year is a discussion of bariatric surgery in patients with COVID-19 and use of stem cell therapy to treat type 1 diabetes and fatty liver and other ectopic fat problems. The goal of this symposium is to increase practitioners' competence and clinical performance to treat diabetes and its complications and, ultimately, to improve patient outcomes.

\section{Register Today! ccfcme.org/diabetesday22}

Join your colleagues in person or participate virtually from the convenience of your home or office This activity has been approved for AMA PRA Category 1 Credits", ANCC Contact Hours and AAPA Category 1 CME Credits. 